\title{
The Acid-Catalyzed Fission of $\beta$-Keto Sulfides in the Presence of Mercaptans. Examples of the Reaction and Studies of the Mechanism
}

\author{
CHRISTOFFER RAPPE and ROLAND GUSTAFSSON \\ Institute of Chemistry, University of Uppsala, Box 531, S.751 21 Uppsala 1, Sweden
}

\begin{abstract}
Several examples are given for the acid-catalyzed fission of $\beta$-keto sulfides. Hydroiodic and hydrobromic acid catalyze the reaction, and trifluoroacetic acid is a useful solvent. The mechanism is suggested to consist of a protonation of the keto group followed by a nucleophilic attack on the sulfide by the halide ion.
\end{abstract}

$\mathbf{I}_{\mathrm{t}}^{\mathrm{n}}$

general, organic sulfides are more resistant to fission by hydrohalic acids than ethers. If the sulfide holds electron-donating groups, the tendency for fission increases.

Iskander studied the acid-catalyzed fission of keto sulfides I and II. ${ }^{1}$ He found that I, contrary to II, reacted with boiling alcoholic hydrogen<smiles>CCCCCC(SC(CC)C(=O)c1ccccc1)C(=O)OCCCC</smiles>

(I)

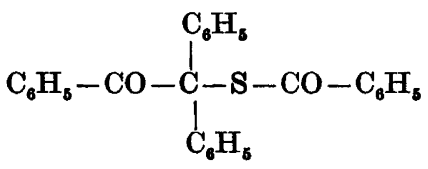

(II)

chloride. Both ketones were cleaved by concentrated sulfuric acid, and Iskander proposed that the initial step in this fission is an addition of a proton to the sulfur atom. This step was proposed to be followed by hydrolysis of the sulfonium salt. ${ }^{1}$ The same initial step followed by a fission to mercaptan and carbonium ion was proposed by Gierer and Alfredsson, who studied the acidcatalyzed fission of some 4,4'-dihydroxydibenzyl sulfides and $\beta$-keto sulfides. ${ }^{2}$

In 1960 it was found by Rappe that some 3-substituted derivatives of levulinic acid were reduced by thioglycolic acid in acid media. ${ }^{3}$ 3-Carboxymethylthio-levulinic acid (III) and 3,4,4-tris-(carboxymethylthio)-valeric acid (IV) were reduced to 4,4-bis-(carboxymethylthio)-valeric acid (V), see Scheme 1.3 Dithiodiglycolic acid was also isolated as a reaction product. 
$\mathrm{CH}_{3} \mathrm{COCHCH}_{2} \mathrm{COOH}$

(III)

$\mathrm{H}^{+} \downarrow 2 \mathrm{HSCH}_{2} \mathrm{COOH}$

$\frac{3 \mathrm{HSCH}_{2} \mathrm{COOH}}{\mathrm{H}^{+} \downarrow}$

$\mathrm{CH}_{8} \mathrm{C}\left(\mathrm{SCH}_{2} \mathrm{COOH}\right)_{8} \mathrm{CH}_{2} \mathrm{CH}_{2} \mathrm{COOH}$

(V)

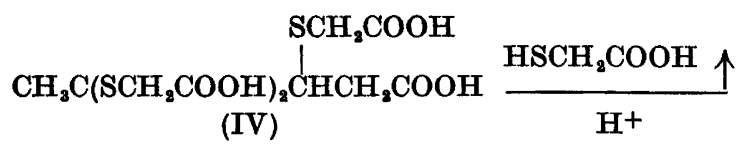

Scheme 1.

It was also found that under the conditions used, the corresponding 5-isomers were not reduced. ${ }^{3}$ In the present paper we have studied other examples of this acid-catalyzed fission of $\beta$-keto sulfides and the mechanism of the reaction.

\section{EXAMPLES OF THE REDUCTION}

We started to study 3-carboxymethylthio-3-benzoylpropionic acid (VI), due to the similarity between this acid and the derivatives of levulinic acid studied before. ${ }^{3}$ This acid was prepared from 3-bromo-3-benzoylpropionic acid and disodium thioglycolate. When VI was heated with one equivalent of thioglycolic acid using hydrobromic acid as catalyst, it was reduced to 3benzoylpropionic acid, see Scheme 2. Contrary to the derivative of levulinic

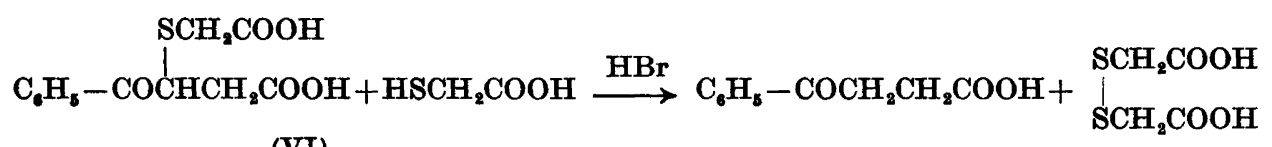

Scheme 2.

acid (III), the keto group did not react, even if excess thioglycolic acid was used.

Other $\beta$-keto sulfides were prepared in the same way from a bromo- or chloroketone and a mercaptide, and their fission was studied. All of them were reduced when hydroiodic acid was used, and in general the keto group was not attacked. The reduction could be written in a general formula, see Scheme 3. The examples are collected in Table 1.<smiles>[R]C[R]SS[R7]S[R7]</smiles>

Scheme 3.

Acta Chem. Scand. 22 (1968) No. 9 
Table 1. Examples of acid-catalyzed fission of $\beta$-keto sulfides.

\begin{tabular}{|c|c|c|}
\hline Compound & $\mathbf{H B r}$ & HI \\
\hline 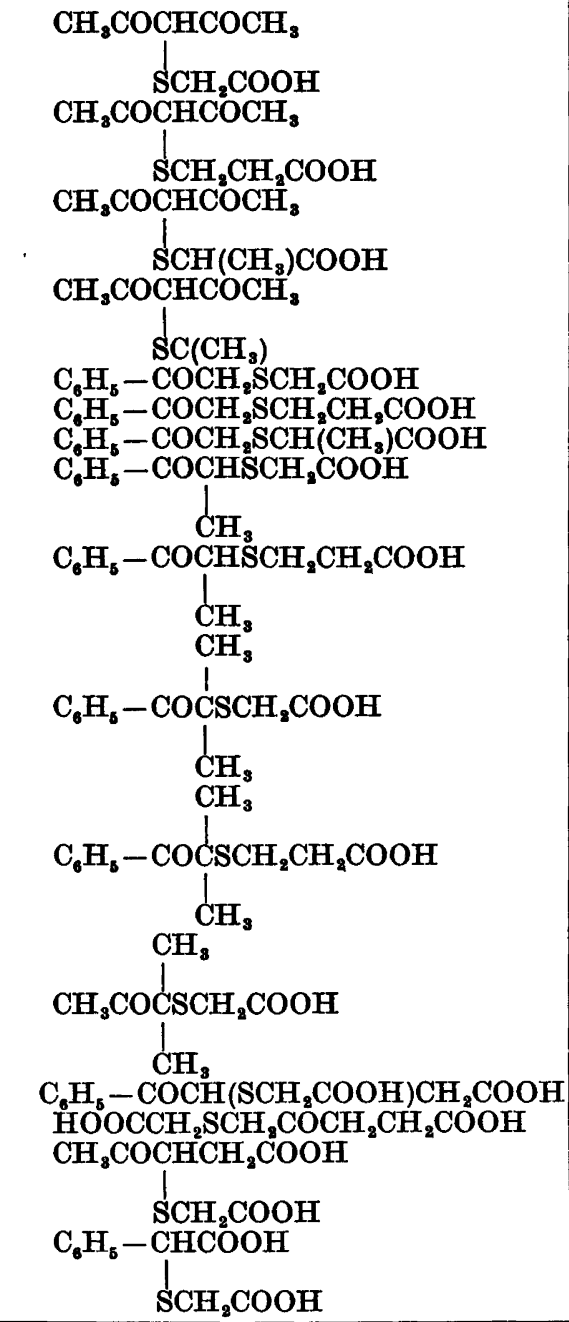 & $\begin{array}{l}(+) \\
(+) \\
(+)\end{array}$ & $\begin{array}{l}+ \\
+ \\
+ \\
+\end{array}$ \\
\hline
\end{tabular}

A useful finding was that use of trifluoroacetic acid as solvent markedly accelerated the reaction, which proceeded by a measurable rate at room temperature and could be followed by NMR in this solvent. However, it was observed that addition of hydrogen halide was necessary for the reduction. 


\section{STUDIES ON THE MECHANISM OF THE REACTION}

In order to study the mechanism of this reaction we followed three main lines: variation of the components, trapping of intermediates in the presence of a mercaptan or a disulfide, and estimation of the reaction rates for different components and conditions.

By changing the substituents $R_{1}, R_{2}, R_{3}$, and $R_{4}$ in the $\beta$-keto compound and $R_{5}$ in the mercaptan (see Scheme 3 ) it is possible to obtain information about the nature of the reaction.

Among the $\beta$-keto sulfides in Table 1 are some that have no enolizable protons. Since these $\beta$-keto sulfides are among those which are most easily reduced to the parent ketone it can be concluded that a prior enolization of the ketone is not involved in the reaction scheme.

In the cases where the starting $\beta$-keto sulfides were prepared from thioglycolic acid, and this sulfide was then treated with thioglycolic acid and hydrohalic acid, it was not possible to establish whether both parts of dithiodiglycolic acid came from the same or from different components of the reaction. In order to study this problem another mercaptan than thioglycolic acid was used. In this case either one unsymmetric or two symmetric disulfides could be formed. In the case where thiophenol was used the three possible disulfides were isolated at the end of the reaction. However, if the reaction was followed by NMR it could be established that an unsymmetric disulfide was the primary product, and in a secondary reaction the two symmetric disulfides were formed. It is well known that unsymmetric disulfides are disproportionated under various conditions. ${ }^{\mathbf{4 - 6}}$

Now the question arises how the disulfide $\left(R_{4}-S-S-R_{5}\right)$ is formed. It is known that disulfides can be formed from sulfenyl halides and mercaptans, ${ }^{7}$ and therefore one possible intermediate in the present reduction would be the sulfenyl halide, $R_{4}-S-X$, which reacts with the mercaptan, $\mathrm{R}_{5}-\mathrm{SH}$, yielding the disulfide.

In two experiments, using hydrogen bromide and 2-carboxymethylthio-, and 2-carboxyethylthio-2-methyl-3-phenyl-3-propanone, respectively, the mercaptan was omitted. Here it was found that the reaction followed the overall formula C, Scheme 4 .
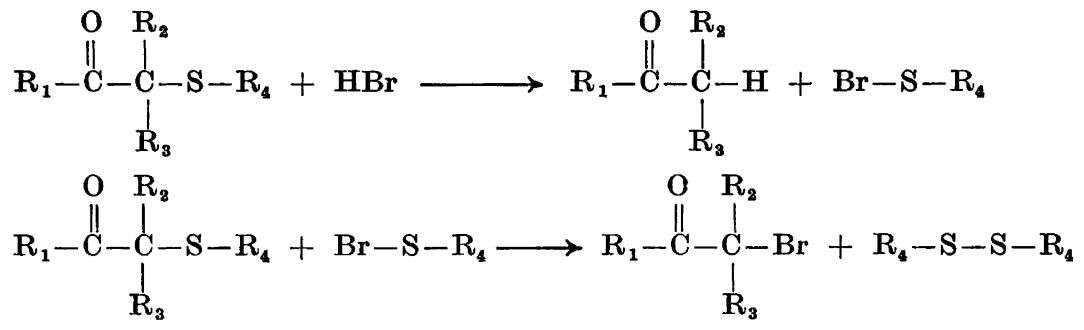<smiles>[R2]SSS[R2]</smiles>

Scheme 4.

Acta Chem. Scand. 22 (1968) No. 9 
The observation of a bromoketone among the products can be taken as an indication of an intermediate sulfenylbromide, which in the absence of a mercaptan reacts with the starting $\beta$-keto sulfide yielding bromoketone and disulfide, see reactions $A$ and $B$, Scheme $4 .^{5}$

If hydroiodic acid was used instead of hydrobromic acid in these experiments, the resulting compounds were reduced ketone, iodine, and disulfide. It is known that in acid medium $\alpha$-iodoketones react with sodium iodide with the formation of ketone and free iodine. ${ }^{8}$

The best indications of an intermediate sulfenylhalide were obtained from an experiment with 3-carboxymethylthio-2,4-pentanedione, hydrobromic acid, and diphenyldisulfide in trifluoroacetic acid. From this reaction $65 \%$ of the mixed disulfide was isolated. Moore and Porter have reported that sulfenylhalides react with disulfides giving a new disulfide. ${ }^{9}$

It has recently been reported that sulfenyl halides also react with sulfides yielding disulfide and a halogenated product. ${ }^{5}$ Another possibility for the formation of the bromoketone is a reaction between the sulfenyl bromide and the ketone yielding bromoketone and mercaptan, but this reaction seems to be excluded by the fact that $\beta$-keto sulfides are usually formed in the reaction between ketones and sulfenyl halides. ${ }^{7}$

Since the reduction could also be performed in the absence of mercaptans, it seems plausible to assume that the mercaptans do not play any central role in the reduction. Additional support for this assumption is given in Fig. 1, where it is found that the first-order rate constant was the same in two experiments with one, respectively two, equivalents of mercaptan present.

It could also be established that the hydrohalic acids differ markedly in efficiency in catalyzing the reaction. The effect of hydroiodic acid was much greater than that of hydrobromic acid. In fact the reduction with hydroiodic acid was too fast to measure; $c f$. Ref. 10. Hydrochloric acid and sulfuric acid were without effect under the conditions employed.

By following the cleavage reaction by NMR a preliminary investigation of the reaction rates for the different $\beta$-keto sulfides could be performed. The derivatives of 2,4-pentanedione were found to react much faster than
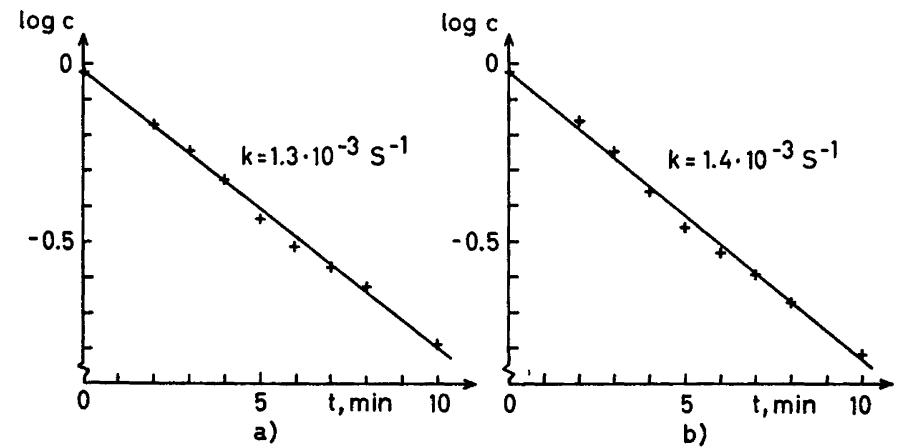

Fig. 1. Cleavage of 3-carboxymethylthio-2,4-pentanedione in the presence of a) one equivalent, b) two equivalents of thioglycolic acid. Solvent trifluoroacetic acid. $0.1 \mathrm{ml}$ $68 \%$ hydrobromic acid added to $2 \mathrm{ml}$ of a $1 \mathrm{M}$ solution.

Acta Chem. Scand. 22 (1968) No. 9 
Table 2. Amount $\beta$-keto sulfide reacted after $6 \mathrm{~min}$ in $\% .0 .001$ mole of $\beta$-keto sulfide in $2 \mathrm{ml}$ trifluoroacetic acid. $0.1 \mathrm{ml} 62 \%$ hydrobromic acid added.

\begin{tabular}{|c|c|}
\hline Compound & Percent reacted in $6 \mathrm{~min}$ \\
\hline $\begin{array}{c}\mathrm{CH}_{3} \mathrm{COCHCOCH} \\
\int_{3} \\
\mathrm{SC}\left(\mathrm{CH}_{3}\right)_{3}\end{array}$ & 7 \\
\hline $\begin{array}{l}\mathrm{CH}_{3} \mathrm{COCHCOCH}_{3} \\
\left.\right|_{\mathrm{SCH}\left(\mathrm{CH}_{3}\right) \mathrm{COOH}}\end{array}$ & 15.5 \\
\hline $\begin{array}{c}\mathrm{CH}_{3} \mathrm{COCHCOCH}_{3} \\
\int_{\mathrm{SCH}_{2} \mathrm{COOH}}\end{array}$ & $\mathbf{5 5}$ \\
\hline $\begin{array}{l}\mathrm{CH}_{3} \mathrm{COCHCOCH}_{3} \\
\quad \mathrm{SCH}_{2} \mathrm{CH}_{2} \mathrm{COOH}\end{array}$ & 56.5 \\
\hline$\underset{\mathrm{C}_{6} \mathrm{H}_{6} \mathrm{COCSCH}}{\mathrm{CH}_{3} \mathrm{COOH}}$ & 0.1 \\
\hline $\mathrm{C}_{6} \mathrm{H}_{5}-\mathrm{COCH}_{2} \mathrm{SCH}_{8} \mathrm{COOH}$ & Too slow to measure \\
\hline
\end{tabular}

the other $\beta$-keto sulfides. It was also found that branching the ketonic part of the molecule $\left(R_{2}\right.$ and $\left.R_{3}=a l k y l\right)$ increased the reaction rates. Moreover, variation in the $R_{4}$ part of the $\beta$-keto sulfides also caused changes in the reaction rate, but branching at the $\alpha$-carbon in this group caused a decrease in

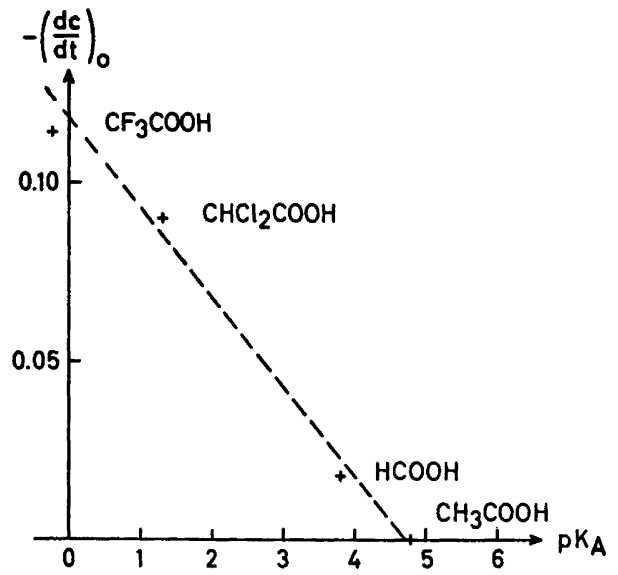

Fig. 2. The effect of the solvent upon the reaction rate. $(0.001$ mole 3-carboxymethylthio-2,4-pentanedione in $1 \mathrm{ml}$ of the solvent. $0.1 \mathrm{ml} 62 \%$ hydrobromic acid added). 
the reaction rate, see Table 2 . It was also found that derivatives of acetophenone reacted faster than derivatives of acetone; see Table 1.

In all the reactions trifluoroacetic acid has been used as solvent. Some other organic acids could also be used, e.g. dichloroacetic acid and formic acid, but not acetic acid. It was observed that the reaction rates in the different solvents were proportional to the $\mathrm{p} K_{\mathrm{A}}$ of the solvent; see Fig. 2.

\section{CONCLUSIONS}

From the discussion above we have learned the following about the mechanism of the reaction:

1. No enolization is involved in the first step of the reaction.

2. There exists a relationship between reaction rates and the acidity of the solvent.

3. The disulfides are primarily formed from two different components.

4. The mercaptans do not play any central role.

5. Sulfenyl halides seem to be intermediates in the reaction.

The relationship between the reaction rates and the acidity of the solvent (Fig. 2) indicates that a protonation is a very important step in the reaction. In the $\beta$-keto sulfide molecule we have two positions where protonation is possible: the sulfur atom or the keto group. Protonation of the sulfur atom has previously been proposed to be involved in the fission of sulfides., ${ }^{1,2}$ It has been suggested that the protonated sulfide either was cleaved into mercaptan and carbonium ion ${ }^{2}$ or it was hydrolyzed. ${ }^{1}$ In the present case both these mechanisms can be excluded: the hydrolysis because in a hydrolysis quite different products should be expected than those obtained. The cleavage of protonated sulfides into mercaptans and carbonium ions has recently been studied by Olah et al. by $\mathrm{NMR}$-technique in $\mathrm{HSO}_{3} \mathrm{~F}-\mathrm{SbF}_{5}-\mathrm{SO}_{2}$ solution at $-60^{\circ} \mathrm{C} .11$ In spite of this highly acidic medium, they found that protonated sulfides, except for tertiary ones, are resistant to cleavage up to $+70^{\circ} \mathrm{C}$. Moreoyer, in the present case the derivatives of 2,4-pentanedione and other $\beta$-diketones were those which reacted most easily, but the corresponding carbonium ion with a positive charge between the two keto groups would be highly unstable.

It has been mentioned above that the hydrohalic acids differed markedly in catalytic power. Thus they cannot take part only as acids, because in such a case it is difficult to explain why sulfuric acid has almost no effect on the reaction. The efficiency of the hydrohalic acids runs parallel to the nucleophilicity of the anions, ${ }^{12}$ and therefore it can be assumed that hydroiodic and hydrobromic acid take part in a nucleophilic attack. Additional support for this view is the observation that potassium iodide is also an efficient cleaving agent for the more reactive $\beta$-keto sulfides.

Thus the protonated sulfide can react in a third way. By analogy with the ether cleavage, ${ }^{13}$ it can react with a halide ion giving a haloketone and a mercaptan as the primary products which then yield ketone and sulfenyl halide; see Scheme 5 upper route. It has been proposed by Iskander that 


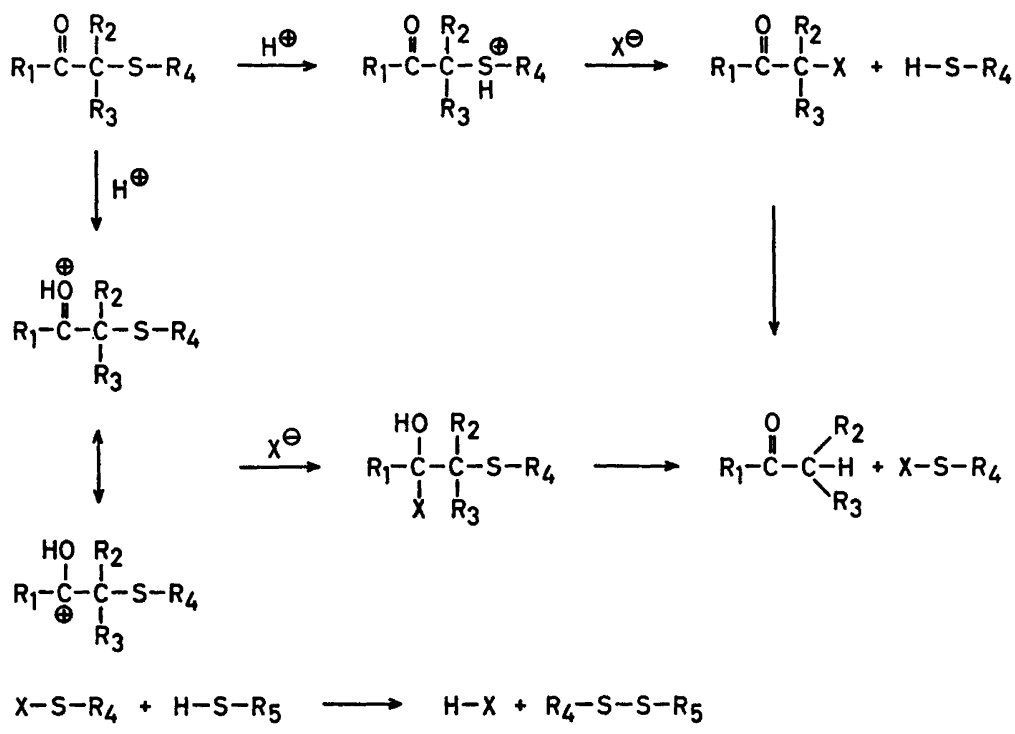

Scheme 5

sulfenyl halides are intermediates in the reduction of haloketones by mercaptans. ${ }^{14}$

An increasing number of papers concerning the protonation of carbonyl compounds have been published in the last years. ${ }^{15-19}$ Thus the first steps in the cleavage of $\beta$-keto sulfides can be protonation of the keto group followed by a nucleophilic attack on the keto carbon, yielding ketone and sulfenyl halide; see Scheme 5, lower route. (A nucleophilic attack on the neutral sulfur atom in the protonated $\beta$-keto sulfide seems less plausible).

At the present state it is difficult to distinguish between the two mechanisms outlined in Scheme 5. However, it is difficult to understand the complete inertness of phenyl-carboxymethylthio-acetic acid (Table 1) if the mechanism contains only reactions at the sulfur atom. Additional indication for the mechanism of the keto group protonation is the observation that the $\beta$-keto sulfides, which are found to be the most easily reduced are those derivatives of $\beta$-diketones where the corresponding $\alpha$-bromo ketone is very easily reduced. ${ }^{20}$ This indicates that similar mechanisms can operate in the two reactions. In the reduction of $\alpha$-bromo ketones it has been found that bromo ketones without enolizable hydrogens also react, ${ }^{21}$ and the mechanism is proposed to be the addition of hydrogen bromide over the keto group, followed by the formation of reduced ketone and halogen. ${ }^{22}$ The halogen molecule can halogenate the starting haloketone or the reduced ketone. ${ }^{23,24}$ 


\section{EXPERIMENTAL}

NMR measurements were carried out on a Varian A-60 spectrometer. Where not otherwise stated the solvent is trifluoroacetic acid with TMS as an internal standard.

The $\beta$-keto sulfides were prepared from the proper bromo- or chloroketone and a sodium mercaptide by a general procedure exemplified by the synthesis of 3-carboxymethylthio-2,4-pentanedione.

3-Carboxymethylthio-2,4-pentanedione. A solution of $4 \mathrm{~g}$ sodium hydroxide in $50 \mathrm{ml}$ of water was added dropwise and with stirring to a mixture of $4.65 \mathrm{~g}$ of thioglycolic acid and $6.73 \mathrm{~g}$ of 3-chloro-2,4-pentanedione. The mixture was allowed to stand at room temperature for one hour. The $\mathrm{pH}$ of the solution was about 5 at the end of that time. After acidification with hydrochloric acid, the mixture was extracted three times with ether. The combined extracts were dried with $\mathrm{MgSO}_{4}$ and evaporated. The residue weighed $7.6 \mathrm{~g}(79 \%)$, m.p. $70-76^{\circ}$. After three recrystallizations from carbon tetrachloride the m.p. was 85-86 . Total yield $5.1 \mathrm{~g}(60 \%)$.

NMR spectrum (in chloroform): Two singlets at $\delta=2.45 \mathrm{ppm}$ and $\delta=3.27 \mathrm{ppm}$ and a very broad peak in the region $\delta=9-10 \mathrm{ppm}$. The integrated areas of the two first peaks were 3:1. (Found: $\mathrm{C} 44.19 ; \mathrm{H}$ 5.25; $\mathrm{S}$ 16.86. Calc. for $\mathrm{C}_{7} \mathrm{H}_{10} \mathrm{O}_{4} \mathrm{~S}: \mathrm{C} 44.20 ; \mathrm{H}$ 5.30; S 16.86).

3-( $\beta$-Carboxyethylthio)-2,4-pentanedione. This compound was prepared from $5.3 \mathrm{~g}$ $\beta$-mercaptopropionic acid and $6.7 \mathrm{~g}$ 3-chloro-2,4-pentanedione. Yield $8.8 \mathrm{~g}(91 \%)$. M.p. $74-75^{\circ}$ (from carbon tetrachloride). NMR spectrum: a singlet at $\delta=2.60 \mathrm{ppm}$ and a multiplet at $\delta=2.9 \mathrm{ppm}$, integrated 3:2. (Found: C 46.73; H 5.88; S 16.02. Calc. for $\mathrm{C}_{8} \mathrm{H}_{12} \mathrm{O}_{4} \mathrm{~S}$ : $\mathrm{C} 47.04 ; \mathrm{H} 5.92 ; \mathrm{S} \mathrm{15.70)}$.

3-( $\alpha$-Carboxyethylthio)-2,4-pentanedione. This substance was prepared from $5.3 \mathrm{~g} \alpha$ mercaptopropionic acid and $6.7 \mathrm{~g}$ 3-chloro-2,4-pentanedione. Yield $9.0 \mathrm{~g} \mathrm{(98 \% ).} \mathrm{Re-}$ crystallization from carbon tetrachloride and light petrol gave m.p. 92-93.. NMR spectrum: a doublet at $\delta=1.55 \mathrm{ppm}(J=7 \mathrm{cps})$, a singlet at $\delta=2.59 \mathrm{ppm}$ and a quartet at $\delta=3.56 \mathrm{ppm}(J=7 \mathrm{cps}$ ), integrated 3:6:1. (Found: C 47.24; H 5.93; S 15.67. Calc. for $\mathrm{C}_{8} \mathrm{H}_{12} \mathrm{O}_{4} \mathrm{~S}$ : $\mathrm{C} 47.04 ; \mathrm{H}$ 5.92; S 15.70).

3-(tert-Butylthio)-2,4-pentanedione. This sulfide was prepared from $9.0 \mathrm{~g}$ tert-butylmercaptan and $13.5 \mathrm{~g}$ 3-chloro-2,4-pentanedione in $50 \mathrm{ml}$ alcohol-water (1:1). The reaction was rather slow. After the sodium hydroxide solution was added, the mixture was allowed to stand at room temperature over night before it was worked up. Yield $15.2 \mathrm{~g}$ $(81 \%)$. B.p. $102-105^{\circ} / 18 \mathrm{~mm} . n_{\mathrm{I}}{ }^{23}=1.5058$. NMR spectrum (neat): three singlets at $\delta=1.06 \mathrm{ppm}, \delta=2.20 \mathrm{ppm}$, and $\delta=17.25 \mathrm{ppm}$, integrated 9:6:1. (Found: C 57.43; H 8.58; $\mathrm{S}$ 17.05. Calc. for $\mathrm{C}_{9} \mathrm{H}_{18} \mathrm{O}_{2} \mathrm{~S}: \mathrm{C} 57.41 ; \mathrm{H}$ 8.57; $\mathrm{S} 17.03$ ).

The prepared derivatives of 2,4-pentanedione seem all to be completely enolized in chloroform.

3-Methyl-3-carboxymethylthio-2-butanone. Prepared from $9.2 \mathrm{~g}$ thioglycolic acid and $16.7 \mathrm{~g}$ 3-methyl-3-bromo-2-butanone. In this case it was necessary to remove the last traces of the ether by an oil pump to obtain a crystalline product. Yield $15.1 \mathrm{~g} \mathrm{(86 \% ).}$ Recrystallization from light petrol gave m.p. 59-60.5 ${ }^{\circ}$ NMR spectrum: three singlets at $\delta=1.67 \mathrm{ppm}, \delta=2.59 \mathrm{ppm}$, and $\delta=3.48 \mathrm{ppm}$, integrated 6:3:2. (Found: $\mathrm{C} 47.70$; $\mathrm{H}$ 6.84; $\mathrm{S}$ 18.14. Calc. for $\mathrm{C}_{7} \mathrm{H}_{12} \mathrm{O}_{3} \mathrm{~S}$ : $\mathrm{C}$ 47.70; $\mathrm{H}$ 6.86; $\mathrm{S}$ 18.20).

$\alpha$-Carboxymethylthio-acetophenone. Prepared according to Holmberg. ${ }^{25}$ Yield $82 \%$, m.p. $99-100^{\circ}$. Holmberg has given the yield $87 \%$ and m.p. $100-102^{\circ}$. NMR spectrum: two singlets at $\delta=3.50 \mathrm{ppm}$ and $\delta=4.21 \mathrm{ppm}$, and the aromatic pattern in the region $\delta=7.5-8.2 \mathrm{ppm}$, integrated 2:2:5.

(1-Benzoyl-1-methylethylthio)-acetic acid. Prepared according to Iskander and Tewfik. ${ }^{26}$ Yield $55 \%$, m.p. $74-75^{\circ}$. NMR spectrum: two singlets at $\delta=1.67 \mathrm{ppm}$ and $\delta=3.56$ ppm, and the aromatic pattern in the region $\delta=7.4-8.2 \mathrm{ppm}$, integrated 6:2:5.

$\beta$-(1-Benzoyl-1-methylethylthio)-propionic acid. Yield 60\%, m.p. 85.5-87.5 . Yield $62 \%$ and m.p. $84^{\circ}$ is given in Ref. 26. NMR spectrum: a singlet at $\delta=1.67 \mathrm{ppm}$, a multiplet at $\delta=2.88 \mathrm{ppm}$, and the aromatic pattern at $\delta=7.5-8.3 \mathrm{ppm}$, integrated 6:4:5.

( $\alpha$-Benzoylethylthio)-acetic acid. This compound was prepared in $80 \%$ yield, m.p. $53-54^{\circ} \mathrm{C}$. It has previously been described as an oil in Ref. 27, where no yield was given. (Found: C 58.87; H 5.32; S 14.29. Calc. for $\mathrm{C}_{11} \mathrm{H}_{12} \mathrm{O}_{3} \mathrm{~S}$ : $\mathrm{C}$ 58.91; H 5.39; S 14.29). NMR spectrum: a doublet at $\delta=1.68 \mathrm{ppm}(J=7 \mathrm{cps})$, a singlet at $\delta=3.54 \mathrm{ppm}$, a quartet at $\delta=4.88 \mathrm{ppm}(J=7 \mathrm{cps})$, and the aromatic pattern at $\delta=7.6-8.3 \mathrm{ppm}$, integrated 3:2:1:5. 
$\beta$-( $\alpha$-Benzoylethylthio)-propionic acid. Yield 85\%, m.p. 64-65 ${ }^{\circ}$ Iskander gave 90\% yield and m.p. $64^{\circ} .^{26}$ NMR spectrum: a doublet at $\delta=1.70 \mathrm{ppm}(J=7 \mathrm{cps})$, a multiplet at $\delta=2.9 \mathrm{ppm}$, a quartet at $\delta=4.72 \mathrm{ppm}(J=7 \mathrm{cps})$, and the aromatic pattern at $\delta=7.6-$ $8.3 \mathrm{ppm}$, integrated $3: 4: 1: 5$.

$\boldsymbol{\beta}$-(Benzoylmethylthio)-propionic acid. This compound was prepared in $89 \%$ yield, m.p. 58-60 $0^{\circ} \mathrm{C}$ after three recrystallizations. Iskander and Tewfik gave the m.p. $63-65^{\circ} \mathrm{C}$. NMR spectrum: a multiplet at $\delta=2.99 \mathrm{ppm}$, a singlet at $\delta=4.18 \mathrm{ppm}$, and the aromatic part at $\delta=7.6-8.3 \mathrm{ppm}$, integrated 4:2:5.

$\alpha$-(Benzoylmethylthio)-propionic acid. Yield $90 \%$ m.p. 88-89 . The m.p. 88-89 is given in Ref. 28. NMR spectrum: a doublet at $\delta=1.55 \mathrm{ppm}(J=7.5 \mathrm{cps})$, a quartet at $\delta=3.74 \mathrm{ppm}(J=7.5 \mathrm{cps})$, a singlet at $\delta=4.34 \mathrm{ppm}$, and the aromatic multiplet at $\delta=7.5-8.3 \mathrm{ppm}$, integrated $3: 1: 2: 5$.

Phenyl-carboxymethylthio-acetic acid." This compound was prepared according to Fitger. ${ }^{29}$ Yield $61 \%$, m.p. $132-133^{\circ}$. Fitger gives the m.p. $132-133^{\circ}$. NMR spectrum: the methylene protons give rise to an $\mathrm{AB}$ spectrum (due to the asymmetric carbon atom) centered at $\delta=3.42 \mathrm{ppm} . J_{\mathrm{AB}}=16 \mathrm{cps},\left|v_{\mathrm{A}}-v_{\mathrm{B}}\right|=7.5 \mathrm{cps}$. In addition there is a singlet at $\delta=5.00 \mathrm{ppm}$, and the aromatic pattern at $\delta=7.2-7.6 \mathrm{ppm}$, integrated 2:1:5.

3-Benzoyl-3-carboxymethylthio-propionic acid. This substance was prepared from $12.9 \mathrm{~g}$ 3-benzoyl-3-bromopropionic acid and $4.6 \mathrm{~g}$ thioglycolic acid. Acidification gave an oil which crystallized in the refrigerator. Recrystallization from water gave m.p. $148-149^{\circ}$. Yield $11.0 \mathrm{~g}(80 \%)$.

NMR spectrum: a singlet at $\delta=3.05 \mathrm{ppm}$ overlaps the AB-part of an ABX spectrum in the region $\delta=2.48-3.35 \mathrm{ppm}$, the $X$-part appears at $\delta=4.60 \mathrm{ppm}$ (quartet) and the aromatic multiplet at $\delta=7.0-7.8 \mathrm{ppm}$, integration $4: 1: 5$. $J_{\mathrm{AB}}=18 \mathrm{cps}$, $\left|J_{\mathrm{AX}}+J_{\mathrm{BX}}\right|=14.5 \mathrm{cps}$. (Found: $\mathrm{C}$ 53.72; $\mathrm{H} 4.49 ; \mathrm{S}$ 11.86. Calc. for $\mathrm{C}_{12} \mathrm{H}_{12} \mathrm{O}_{5} \mathrm{~S}$ : $\mathrm{C} 53.72$; $\mathrm{H}$ 4.51; S 11.95).

3- and 5-Carboxymethylthio-levulinic acid were prepared according to Ref. 3.

Reaction between 3-benzoyl-3-carboxymethylthio-propionic acid and thioglycolic acid. To a melt of $2.68 \mathrm{~g} \mathrm{3-benzoyl-3-carboxymethylthio-propionic} \mathrm{acid,} 0.92 \mathrm{~g}$ of thioglycolic acid was added, followed by five drops of $48 \%$ hydrobromic acid. The mixture was heated for $3 \mathrm{~h}$ on a waterbath. After two days in the refrigerator the solid cake was treated with cold water. The undissolved crystals weighed $1.4 \mathrm{~g}(79 \%)$, and one recrystallization from water gave m.p. $113-115^{\circ}$. The IR-spectrum showed that the substance was 3 benzoylpropionic acid.

The water was extracted with ether. Drying over $\mathrm{MgSO}_{4}$ and evaporation gave $0.5 \mathrm{~g}$ slightly yellow crystals, m.p. $105-107^{\circ}$ after one recrystallization from chloroform. The substance was identified as dithiodiglycolic acid from its IR-spectrum.

Phenyl-carboxymethyl-disulfide. a) From diphenyldisulfide and 3-carboxymethylthio2,4-pentanedione. $0.95 \mathrm{~g}$ 3-carboxymethylthio-2,4-pentanedione and $3.27 \mathrm{~g}$ diphenyldisulfide (proportions 1:3) were dissolved in a mixture of $10 \mathrm{ml}$ carbon tetrachloride and $10 \mathrm{ml}$ trifluoroacetic acid (gave two phases). $0.5 \mathrm{ml}$ of $63 \%$ hydrobromic acid was added and the solution was shaken for half an hour. It was then poured into $75 \mathrm{ml}$ of water. The lower layer was separated and the water layer was extracted with carbon tetrachloride. The combined organic phases were extracted with a bicarbonate solution, which was acidified with hydrochloric acid and extracted with carbon tetrachloride. Evaporation after drying over $\mathrm{MgSO}_{4}$ gave $0.65 \mathrm{~g} \mathrm{(65 \% )}$ phenyl-carboxymethyl-disulfide, m.p. $39-41^{\circ}$. The m.p. $41^{\circ}$ is given in the literature. ${ }^{30}$ NMR spectrum (in carbon tetrachloride); a singlet at $\delta=3.40 \mathrm{ppm}$, an aromatic multiplet at $\delta=7.1-7.7 \mathrm{ppm}$, and a singlet at $\delta=11.94 \mathrm{ppm}$, integrated 2:5:1.

b) From thiophenol and 3-carboxymethylthio-2,4-pentanedione. $1.10 \mathrm{~g}$ thiophenol and $1.90 \mathrm{~g} \mathrm{3-carboxymethylthio-2,4-pentanedione} \mathrm{were} \mathrm{dissolved} \mathrm{in} \mathrm{a} \mathrm{mixture} \mathrm{of} 2 \mathrm{ml}$ carbon tetrachloride and $2 \mathrm{ml}$ trifluoroacetic acid. $0.1 \mathrm{ml}$ of $63 \%$ hydrobromic acid was added and the intensely red coloured solution was allowed to stand at room temperature for $24 \mathrm{~h}$ and was then worked up as in (a). This gave $0.452 \mathrm{~g}$ phenyl-carboxymethyl-disulfide, m.p. $39-41^{\circ}, 0.431 \mathrm{~g}$ diphenyldisulfide, m.p. $57-59^{\circ}$, and $0.245 \mathrm{~g}$ dithiodiglycolic acid, m.p. $90-95^{\circ}$ (by extraction of the aqueous layer with ethyl acetate after the extraction with carbon tetrachloride). By extraction of the acidified bicarbonate solution with ethyl acetate $0.08 \mathrm{~g}$ of 3-carboxymethylthio-2,4-pentanedione, m.p. 81 $85^{\circ}$, was recovered unchanged. 
It is of great importance that all the mercaptan has reacted before the extraction with bicarbonate solution, otherwise this will cause a very rapid equilibrium between the possible disulfides. ${ }^{4,6}$

Estimation of reaction rates. The runs were carried out at the temperature of the probe, which was about $39^{\circ} \mathrm{C}$. A typical run consisted of 0.001 mole of a $\beta$-ketosulfide, which was dissolved in a known amount of trifluoroacetic acid at $40^{\circ}$, or, if a mercaptan was also used, the components were dissolved and diluted to a known volume. The hydrohalic acid was added by a pipette and was carefully mixed with the solution before part of it was transferred to an NMR tube. Integration was performed over a growing and a disappearing peak and the percent reaction was calculated.

The symmetrical disulfides could be isolated by dilution with water, extraction with ether, and evaporation. They were identified by their melting points and IR-spectra. When a mixed disulfide could be formed, a complex mixture resulted. Separation was possible when thiophenol was used. Identification of the resulting ketones and bromoketones was possible by comparison of the NMR spectra from the reactions with spectra of the expected products.

Cleavage by potassium iodide. $0.34 \mathrm{~g}$ potassium iodide dissolved in $0.4 \mathrm{ml}$ of water was added to a solution of $0.19 \mathrm{~g} \mathrm{3-carboxymethylthio-2,4-pentanedione} \mathrm{in} 3 \mathrm{ml}$ of trifluoroacetic acid. Some potassium iodide precipitated but dissolved during the time of the reaction. A brown colour of free iodine appeared at once. After one hour the reaction was almost complete (NMR), and dithiodiglycolic acid could be isolated. Yield $75 \%$, m.p. $105-107^{\circ}$.

Acknowledgements. The authors are indebted to Professor Arne Fredga for his interest in the present work and for all facilities placed at our disposal. Grants from Magnus Bergvalls Stiftelse to C. R. and from the Faculty of Mathematics and Natural Sciences, University of Uppsala, to R. G. are gratefully acknowledged.

\section{REFERENCES}

1. Iskander, Y. J. Chem. Soc. 19481549.

2. Gierer, J. and Alfredsson, B. Chem. Ber. 90 (1957) 1240.

3. Rappe, C. Arkiv Kemi 16 (1960) 171.

4. Fredga, A. Arkiv Kemi, Mineral. Geol. A 12 (1937) No. 13.

5. Moore, C. G. and Porter, M. Tetrahedron 9 (1960) 58.

6. Foss, O. In Kharasch, N., Ed., Organic Sulfur Compounds, I, Pergamon, Oxford 1961, p. 83.

7. Rappe, C. and Gustafsson, R. Acta Chem. Scand. 22 (1968) 2927.

8. Meyer, K. H. Ann. 380 (1911) 212.

9. Moore, C. G. and Porter, M. J. Chem. Soc. 19582890.

10. Lüttringhaus, A. and v. Sääf, G. Angew. Chem. 51 (1938) 915.

11. Olah, G. A., O'Brien, D. H. and Pittman, Jr., C. U. J. Am. Chem. Soc. 89 (1967) 2996 .

12. Hine, J. Physical Organic Chemistry, McGraw, Tokyo 1962, p. 161.

13. Fieser, L. and Fieser, M. Advan. Org. Chem. New York 1961, p. 308.

14. Iskander, Y., Riad, Y. and Tewfik, R. J. Chem. Soc. 19623232.

15. Palm, V. A., Haldna, U. L. and Talvik, A. J. In Patai, S. The Chemistry of the Carbonyl Group, London 1966, p. 421.

16. Birchall, T. and Gillespie, R. J. Can. J. Chem. 43 (1965) 1045.

17. Brookhart, M., Levy, G. C. and Winstein, S. J. Am. Chem. Soc. 89 (1967) 1735.

18. Viel, C., Waegell, B. and Witz, P. Bull. Soc. Chim. France 19661104.

19. Olah, G. A., Calin, M. and O'Brien, D. H. J. Am. Chem. Soc. 89 (1967) 3586.

20. Kröhnke, F. and Timmler, H. Ber. 69 (1936) 614.

21. Rappe, C. Unpublished results.

22. Newman, M. S. J. Am. Chem. Soc. 73 (1951) 4993.

23. Rappe, C. Arkiv Kemi 23 (1964) 81.

24. Rappe, C. Arkiv Kemi 24 (1965) 73.

Acta Chem. Scand. 22 (1968) No. 9 
25. Holmberg, B. Arkiv Kemi, Mineral. Geol. A 12 (1936) No. 9.

26. Iskander, Y. and Tewfik, R. J. Chem. Soc. 19612393.

27. Behaghel, O. and Ratz, H. Ber. 72 (1939) 1257.

28. Iskander, Y. and Tewfik, R. J. Chem. Soc. 19512050.

29. Fitger, P. Diss., Lund 1924.

30. Jacini, G. and Laurin, F. Gazz. Chim. Ital. 80 (1950) 762.

Received April 9, 1968. 